\title{
SISTEMA CATÓLICO DE EDUCAÇÃo E ENSINO NO BRASIL: uma nova perspectiva organizacional e de gestão educacional
}

\section{Katholisches erziehungs und lehrsystem in Brasilien: aeine neue organisations und schulverwaltungs perspective}

Manoel Alves ${ }^{1}$

\section{Resumo}

A presente reflexão retoma de forma sintética a trajetória da Escola Católica no Brasil com o propósito de situá-la, enquanto instituição social, no conjunto das forças históricas que com ela interagem, especialmente as do mercado de educação privada e das políticas públicas de financiamento em educação. A partir deste contexto analisa sua estrutura organizacional enquanto sistema educacional privado e confessional no atual contexto da educação privada brasileira propondo novas formas de organização em rede e um novo modelo de gestão para poder superar o processo de acentuada retração de sua presença no cenário da educação brasileira em que se encontra. Propomos instaurar o debate sobre a oportunidade e a urgência em implantar um Sistema Católico de Ensino no país.

Palavras-chave: Educação confessional; Redes; Rede de ensino sistema educacional; Modelo organizacional; Mercado educacional.

Doutor em Ciências da Educação pela Universidade de Paris VIII, Professor Adjunto do Programa de Mestrado em Educação da Universidade Católica de Brasília - DF, malves@pos.ucb.br 


\section{Kurzfassung}

Vorliegende Überlegung wiederholt in syntetischer Form den Weg der Katholischen Schule in Brasilien, mit dem Entschluss sie vorzulegen als sociale Einrichtung, im Zusammenhang mit den historichen Streitkräften welche mit ihr zusammen verfahren und arbeiten besonders die des privaten Erziehungsund Bildungsmarkts und deröffentlichen finanziellen Unterstützung der Erziehung. Ab diesem zusammenhängenden Inhalt analysiert sie seine organisationelle Struktur als privatives und confessionelles Erziehungssystem. Im gegenwärtigen Zusammenhang der brasilianischen privativen Erziehung legt sie neue Organisationsformen im Netzwerk vor und ein neues Verwaltungsmodell, um die betonte Einziehung seiner erzieherischen Aktivitäten zu überwinden und seine Gegenwart im Panorama der brasilianischen Erziehung und Bildung, in der sie sich momentan befindet, zu befestigen. Wir schlagen eine Debatte vor, über die Gslegenheit und Günstigkeit eines Katholischen Erziehungs und Bildungssystems im ganzen land Brasilien.

SCHLÜSSELWÖRTER: Confessionelle Erziehung, Netz., Bildungsnetz; Bildungs system; organisatorisches Modell; Erziehungsmarkt.

\section{Breve abordagem histórica}

A trajetória da Escola Católica no Brasil é complexa nas suas relações intra-institucionais, com o Estado e com os diversos segmentos da sociedade organizada. Em sua história, os momentos de tensão foram muitos e de origens diversas. As contradições internas também estiveram presentes. Se ela colaborou com as elites na manutenção da ordem estabelecida, ela também ofereceu resistência às classes hegemônicas, educou parcela das camadas populares e contribuiu de forma decisiva para a formação da nação brasileira.

Em épocas e contextos diferentes, a Igreja e a sua Escola viveram sérios confrontos para poder continuar existindo e se organizando livremente. A união e a organização necessárias em situações como estas, por força de seu esprit de corps, debelaram as ameaças. Em alguns momentos, no entanto, a sua organização mostrou-se inadequada ou fraca, assimilando-lhe pesadas perdas.

Em 1854, o Imperador aprova a Lei de Liberdade de Ensino, complementando o Ato Adicional de 1834, este regulamentar à Constituição de 1824. A partir deste momento começa a expandir-se a rede de escolas da Igreja, sobretudo as de nível secundário, devido às limitações do Estado em atender tal segmento. Mas foi com o advento da República que o seu crescimento mostrou-se extraordinário. Nesse momento, a Educação Católica passa a ser elemento de destaque na estratégia do Episcopado para acelerar o processo 
de romanização da Igreja no Brasil, e para fazer face à rede de escolas protestantes que começam a surgir, um pouco por toda a parte, no território nacional. É justamente neste período, final do século XIX, e nas primeiras décadas deste século, que são fundados no Brasil, ou aqui vêm se instalar, muitas Congregações Religiosas, especialmente os dedicados à educação escolar da juventude, tanto masculina, quanto feminina.

Pela Constituição de 1937, passa a ser possível a destinação de recursos financeiros do Erário para a manutenção da escola particular e confessional. Embora tenha ocorrido com certa profusão, durante algum tempo, a destinação de verbas começa a ficar comprometida, por razões de ordem econômica, mas, sobretudo, por pressão política, a partir dos anos 60. Esse repasse de verbas, que hoje praticamente inexiste, nunca chegou a ser devidamente regulamentado.

Tal lacuna de recursos contribuiu para a evolução de idéias e ideais na relação entre a Escola Católica, a Educação Nacional e o Estado Brasileiro. A organização da Escola Católica também alterou os seus rumos desde então, de modo mais acelerado nas últimas décadas, no âmbito de seus organismos associativos nacionais. A própria criação da ANAMEC (1993) corrobora esta afirmação. Por sua vez, a história da AEC e da ABESC tomou distintos contornos ao longo destes anos. Quatro períodos são bem distintos na trajetória da Escola Católica nas últimas décadas.

O primeiro período, de 1945 a 1962, prolonga a polêmica das décadas anteriores, entre Católicos e Liberais, e a luta da Escola Pública versus Escola Privada. Na Constituinte de 1946, a Escola Católica, sustentada por parcela significativa da Igreja e de seu episcopado, defende a liberdade de ensino e o inalienável direito da família em optar pela educação dos filhos, custeada, se necessário fosse, pelo poder público. Fortifica-se a consciência de se assumir com ardor a tarefa de melhoria das escolas católicas para preparar elites cristãs capazes de influenciar a Sociedade. A maioria das escolas católicas persevera no modelo tradicional, academicista e de matriz humanista, enquanto alguns, sob influência da Escola Nova, propugnam o método montessoriano adaptado por Hélene de Lenval através do Pe. Faure do Institut Catholique de Paris.

O segundo período vai de 1962 a 1979. Coerente com a dinâmica conciliar, a CNBB, em 1962, inicia seu Plano de Emergência. Nessa época inicia-se o boom da escola privada. Um dos temas deste Plano, por influência da JEC e da JUC é o da renovação dos educandários católicos, propondo uma Escola com espírito de família e em estado de missão. Inicia-se a preocupação com a formação extramuros de religiosos e leigos educadores, por meio de cursos e congressos. Fortalecem-se as associações de pais e o apoio ao movimento estudantil. As primeiras greves de professores ocorrem nesse período. 
Fazer da Escola Católica uma Comunidade Escolar é a tônica da Assembléia da AEC em 1965. Pouca importância ocupavam, então, as questões de natureza política e jurídica.

Ainda nesse período é promulgada a LDB, a Lei 4.024 de 21 de dezembro de 1961, que vem dar às escolas maior autonomia na sua organização administrativa, disciplinar e didática, desafiando a Escola Católica a se reorganizar. Também a publicação de Gravissimum Educationis Momentum, em 1965, lança novos desafios sobre a Escola Católica. Multiplicam-se, por força destes fatores conjunturais, as experiências pedagógicas em diversas instituições educacionais católicas.

Nesse período são muitos os que pedem o aggiornamento da Escola Católica. Com a Conferência do Episcopado latino-americano em Medellín Colômbia (1968), questionando a educação no continente e apresentando a educação libertadora como proposta alternativa aos modelos educacionais vigentes, o tradicional e o técnico-desenvolvimentista, a Escola Católica se questiona. Durante a ditadura militar não houve possibilidade de se viabilizar a ruptura que a Educação Libertadora exigia, de antecipar, por seus métodos, seus conteúdos e seus relacionamentos, a nova sociedade. Só é possível continuar com a renovação pedagógica. A dimensão política sucumbe.

Surge um novo debate em tomo da nova LDB, desta vez a Lei 5.692 de 1971. A partir dos anos 60, e de forma mais acentuada na década de 70, assiste-se ao processo de retração da Igreja no campo da educação. Muitos Colégios Católicos fecham as suas portas. No vácuo quantitativo criado pela Igreja, e no vácuo qualitativo criado pelo poder público, ocorre o rápido crescimento da iniciativa privada no campo da educação no Brasil.

O outro período vai de 1979, com a Conferência do Episcopado latino-americano em Puebla - México, até a promulgação da nova Constituição no Brasil (1988). A partir de Puebla e com o processo de abertura política se aprofunda, no país, a dimensão transformadora da Escola Católica com suas possibilidades, seus limites e suas contradições. O Congresso Nacional da Asso ciação de Educação Católica do Brasil - AEC (1980) tem como tema "Educação para a Justiça". A pressão do regime militar e a proximidade da Igreja e dos religiosos com as classes populares e seus movimentos vão abrir outras perspectivas e suscitar reflexões sobre o papel social da Educação e da Escola Católica. As reflexões sofrem a influência das teorias crítico-reprodutivistas.

As distintas visões a respeito da presença da Igreja na educação, especialmente no tradicional campo da Escola Católica, provocam acentuadas divisões entre pessoas, grupos, Congregações Religiosas e setores diversos da Igreja. No bojo desse movimento, o setor privado fortalece a sua posição na educação, assumindo hegemonicamente o seu controle por meio dos Sindicatos Patronais. Parcela das Escolas Católicas adere a tais Sindicatos por vezes de 
modo acrítico, enquanto outra apenas se sujeita a eles. Acentua-se o conflito entre Escola Católica particular, paga e de acesso exclusivo às classes abastadas e uma Igreja que faz declarada Opção Preferencial pelos Pobres.

O quarto e último período prolonga-se de 1988 aos nossos dias. A Igreja retoma, por outros caminhos, a reflexão sobre a pertinência pastoral de sua presença no campo escolar, mais especificamente na manutenção de instituições de educação formal, assumindo as limitações conjunturais de ordem social e econômica que lhe são inerentes. Já não se abandonam as escolas, por opção, com tanta facilidade. Se elas, hoje, encerram suas atividades, o fazem por outras razões, como, por exemplo: falta de recursos, problemas de gestão e impossibilidade de equilíbrio no mercado. Recentemente, os religiosos começam a partilhar responsabilidades com os leigos, ainda que gradativamente, atingindo inclusive cargos de direção.

A discussão da Constituinte em 1988 provoca posicionamentos da Igreja. As greves e conflitos com professores, funcionários e pais proliferam em torno de salários e mensalidades escolares. As freqüentes intervenções arbitrárias e desastrosas do poder público, a manipulação político-partidária do movimento estudantil e das associações docentes, aliadas, por vezes, à intransigência dos Sindicatos Patronais, acentuam os conflitos. Em reposta, a Assembléia dos Bispos se posiciona com o documento 47 de 1992- "Educação, Igreja e Sociedade". O documento apresenta lacunas quanto ao posicionamento oficial da Hierarquia no tocante à missão e à organização de nossas instituições.

Deste documento emanaram 15 teses. Tal posicionamento do episcopado não veio acompanhado de orientações que sinalizassem a estrutura e a organização necessárias à Escola Católica para viabilizar a efetivação das referidas teses. Essa lacuna foi reforçada pelo fato de muitos educadores católicos desejarem continuar com a atual representação patronal (via Sindicatos) para representar a Escola Católica junto à sociedade civil, aos órgãos públicos e aos sindicatos dos professores, parceiros leigos que compartilham a Missão da Educação Católica.

No atual momento em que se aprofundam os desafios para a Escola Católica quanto às isenções decorrentes da "filantropia", inclusive o recente debate sobre a relação entre educação e assistência social; à obtenção de verbas públicas; à política para as mensalidades escolares; à diminuição, ao envelhecimento e ao deslocamento dos efetivos religiosos; ao decréscimo do número de alunos; à agressiva lógica do mercado educacional; à persistência no fechamento de escolas; à crescente e irreversível entrada dos leigos para cargos diretivos em nossas instituições; ao debate e às conseqüências em torno da LDB de 1996 e legislação dela decorrentes, constatamos: 
- primeiro, que a Escola Católica e seus dirigentes vivem esta situação com muita perplexidade;

- segundo, que o posicionamento de organismos de cúpula - Bispos e Superiores Religiosos - é insuficiente, ficando aquém das imperiosas necessidades e expectativas das comunidades escolares;

- terceiro, que as estruturas organizacionais, de articulação e de cooperação da Escola Católica nos níveis local, congregacional, e regional e nacional ainda são fracas.

Tais lacunas deixam a Escola Católica e seus agentes vulneráveis e desprovidos da necessária estrutura para fazer face aos desafios do futuro, seja dos que já podem ser identificados, seja dos que ainda irão surgir.

\section{Aprendendo com a experiência de outros}

Em diversos outros países do mundo a Escola Católica possui distintos modelos de organização, seja sob o ponto de vista jurídico e educacional, seja sob o ponto de vista eclesial. Em geral suas formas de organização refletem as lutas que se enfrentaram para garantir a sua sobrevivência, a sua manutenção financeira e a salvaguarda de sua identidade em contextos pluralistas, geralmente hostis à liberdade de ensino.

A França é um caso lapidar para ilustrar esse ponto de vista. Abolida a liberdade de ensino quando da Revolução Francesa em 1789, a mesma volta a ser reconhecida e definitivamente restabelecida na Constituição do Diretório de 22 de agosto de 1795, desta vez como dispositivo constitucional. No entanto, a legislação para regular esta liberdade virá somente muito mais tarde e por etapas: em 1833 com a Lei Guizot para o ensino primário; em 1850 com a Lei Falloux para 0 ensino secundário e, finalmente, em $1875 \mathrm{com}$ a lei para o ensino superior.

Nem por isso as coisas caminharam tranqüilas. Ao contrário, os conflitos seguiram numerosos. De 1902 a 1905 as escolas católicas são fechadas, por determinação do ministro Combes, e muitos religiosos educadores deixam a França. A reabertura gradativa das escolas se inicia somente após o final da Primeira Grande Guerra.

A partir de muita luta das famílias católicas, a Lei Berange et Marie de 1951 aprova a ajuda financeira às escolas privadas, até que a questão venha a ser finalmente regulamentada com a Lei Debret de 31 de dezembro de 1959. As leis continuam a se suceder e, com elas, a Igreja na França vai ganhando espaço no processo de democratização da Escola Católica por meio de maiores subsídios do poder público. 
A Escola Católica na França tem organização em nível diocesano e nacional. Os serviços de controle e animação são centralizados em Paris no Secrétariat Général de l'Enseignement Catholique, sob os auspícios da Conferência Episcopal. Este organismo possui grande e permanente capacidade de mobilização da população e da opinião pública, bem como adequada estrutura de negociação política. A Escola Católica acolhe 16\% da população escolar francesa e perfaz 93\% das escolas privadas do país. Hoje, neste país laico, um sobre cada três cidadãos franceses passou por uma Escola Católica em algum momento de sua vida escolar.

Em outros países da Europa não foi muito diferente. A Escócia Católica conquistou o espaço e a liberdade para a sua escola, após muita luta, pelo famoso Ato de 1918. Na Bélgica, embora a Lei da Liberdade de Ensino seja de 1831, somente pela Lei do Pacto Escolar de 29 de maio de 1959 foi garantida a subvenção de recursos públicos para a escola privada. Hoje, as Escolas Católicas belgas são subvencionadas pelo Estado. Nesse país, $56 \%$ de suas escolas são privadas, das quais 99\% são católicas, com um total de 1.400 .000 alunos.

Na Holanda ocorreu de forma similar. As Leis de 1917 e 1920 estabeleceram a Liberdade de Ensino e a responsabilidade financeira do Estado para com a manutenção da escola privada, das quais, hoje, 90\% são confessionais: católicas ou protestantes. Na Espanha, onde 40\% das escolas são privadas, sendo $24 \%$ católicas, a subvenção pública foi estabelecida na Constituição de 1978.

Em diversos outros países, as coisas se processaram de modo similar: Dinamarca, Canadá, Alemanha e Irlanda. Em países próximos ao nosso isso já ocorreu. Já foram dados passos na Argentina e, sobretudo, no Chile, em que Escolas Católicas chegam a ser financiadas pelo Estado em até 95\%. Também em países de minoria católica, como a Índia, o Sri Lanka, os Camarões, a África do Sul, entre outros, a adequada organização permitiu à Escola Católica as suas conquistas.

\section{Mundialização e redes: vivendo na aldeia global}

Nos últimos anos tem-se falado muito de mundialização. A expressão exerce fascínio, ao mesmo tempo em que gera repulsa. De modo geral, a realidade que esse conceito tenta traduzir provoca insegurança. Por ele se explicaria a queda da bolsa de valores nos Estados Unidos, da mesma forma que o desemprego no Brasil. Daniel Cohen, professor de Ciências Econômicas em Paris, no seu trabalho intitulado "A terceira revolução industrial para além da mundialização", publicado pela Fundação Saint-Simom, afirma: "a mundi- 
alização tornou-se, em alguns anos, o termo mal-visto pelo qual seria necessário, para uns aceitar as transformações em curso, e para outros lutar para preservar a ordem social conquistada com tanto empenho".

Não deixa de ser admirável como um neologismo, inexistente há apenas mais de uma década, tornou-se tão propalado. Isso se deve certamente ao fato de com ele tentarem designar, de maneira simples e direta, fenômenos complexos e múltiplos que atingem a todos. De modo imediato e direto se reconhece, por esta expressão, que o mundo é cada vez mais um só, e que dele fazemos todos parte, querendo ou não. Esse fenômeno, ou fenômenos, atinge a Igreja, como instituição, projeto evangelizador e enquanto Escola Católica.

A análise habitual do fenômeno da mundialização decorre em primeiro lugar do ponto de vista econômico. Muitas vezes tende-se a resumi-lo a esta dimensão. No entanto, como fenômeno de caráter econômico, ele é antigo e contínuo. Desde as rotas de navegação comercial, existentes já na Antigüidade, com fenícios, gregos ou romanos; e mais tarde com a colonização do Novo Mundo pelos ibéricos, os homens das diferentes regiões do planeta compartilham processos de natureza econômica. Nessa esfera o que se assiste, hoje, é uma aceleração de tais processos, especialmente pela criação de uma esfera financeira global.

Esta aceleração foi provocada, e tornou-se possível, mediatizada pela Tecnologia da Informação, por outra dimensão da mundialização que parece tocar mais de perto os educadores: a globalização da cultura. Assistimos a uma verdadeira revolução tecnológica que, com o apoio de diferentes ciências, estimulou a criação de redes, a codificação de sinais, a transmissão de dados, a informática etc. Em conseqüência assistimos a uma nova forma de hegemonia cultural, cujo principal sintoma é a generalização de uma cultura de matriz ocidental, com forte acento norte-americano.

A globalização da cultura nos aproxima daquela realidade da Aldeia Global prefigurada pela canadense Marshall Mcluhan, em 1962, no seu livro A Galáxia Gutemberg. As cadeias internacionais de imprensa e televisão, como a CNN e outras, a indústria cinematográfica, e as crescentes viagens turísticas ou profissionais, deram a sua contribuição para esse processo. Destaca-se, especialmente, o lugar de protagonista, reservado aos meios de comunicação social.

Armand Mattelart, professor de Ciências da Informação e da Comunicação na Universidade de Rennes, é quem afirma que em matéria de comunicação, o fenômeno da globalização já é um fato. Cada vez mais as sociedades estão conectadas às redes de informação e de comunicação, cuja lógica é funcionar sobre a modalidade "universal". Mas a globalização aplicada ao campo da comunicação é também uma noção "traiçoeira”, pois ela dissimula 
as variáveis da complexidade das novas formas de interação e de transição ao nível planetário. As empresas multinacionais, as redes de agências de publicidade, os grupos da mídia e as redes telemáticas foram promovidos a "atores globais". Globais pela extensão e a acumulação das sinergias entre diversas especialidades, globais por sua ambição geo-estratégica em escala mundial.

Além da dimensão econômica da mundialização, que tem na esfera financeira global o seu carro-chefe, e da globalização da cultura, existe um terceiro aspecto desse processo que decorre e interage com os dois anteriores: as redes planetárias. Tal dimensão se caracteriza pela emergência de fenômenos planetários transnacionais, que põem em xeque o lugar, o papel e a soberania do Estado-Nação, atingido por fluxos e redes de todo tipo: ecológico, defesa dos direitos humanos, religiosos, máfia, tráfico de drogas, comunicações globais, fluxos migratórios, comerciais e de informação, et.; além da constituição de blocos continentais ou mundiais: ONU, Câmara Internacional de Comércio, Organização Internacional do Trabalho, Cruz Vermelha, Grupo dos 7 Grandes, NAFTA, União Européia, OTAN, OCDE e tantos outros.

A globalização, especialmente a econômica, ocupa um lugar de destaque crescente no debate e nos embates entre as mais diferentes esferas contemporâneas. As posições a esse respeito são as mais diversificadas. Existem aqueles que defendem a tese do caos universal, enquanto outros a da mundialização como processo natural de auto-regulamentação para o necessário aumento da riqueza e a conseqüente sobrevivência da humanidade, dentro dos patamares de consumo já conquistados por uma parcela do planeta. Para além dos juízos e dos exercícios de "futurição", sem penetrar nas vantagens e inconvenientes, o que se constata consensualmente é a manifestação de uma nova configuração da economia mundial marcada pela passagem de um sistema regulado pelos Estados para um sistema regulado pelos mercados.

Outra constatação, de que ninguém duvida, nessa nova configuração da economia mundial, é o da importância e o do Poder das Redes. ONGs, empresas multinacionais, seitas, e outras instâncias mais, se inserem no movimento de um crescente reforço das redes no contexto da mundialização, como condição para preservar espaços e dilatar suas capacidades de intervenção em contextos regionais ou nacionais. Numerosas redes concernem os mais variados domínios, tão diferentes como são a economia, a religião e a difusão do saber. Tais redes apontam para a capacidade dos indivíduos de se mobilizar, para se definirem em relação a espaços que transcendem as tradicionais barreiras do Estado-Nação. Esta flexibilidade e adptabilidade das redes devem ser, hoje, senão paradigma, ao menos ponto de referência para questionar a rigidez das atuais estruturas da Escola Católica, lançando luzes sobre o seu futuro. 
Isso não chega a ser uma realidade totalmente nova. Do ponto de vista sociológico, a Igreja Católica é também uma instituição política que viu desenvolver no seu seio redes múltiplas e variadas, cujo caráter transnacional é indiscutível. As dioceses, por exemplo, são Igrejas em rede que ocupam um lugar de destaque na organização sociopolítica do catolicismo no mundo. As estruturas com as quais tradicionalmente as Congregações Religiosas se dotou testemunham da mesma política de internacionalização. A Igreja, como tantas outras "redes transnacionais", opera no encontro de valores e de interesses diversificados e nem sempre convergentes. Se por um lado a experiência de ação e de organização em rede não é nova para a Igreja, por outro lado os seus modelos historicamente já consolidados foram se cristalizando pelos tempos, e obstaculizaram-lhe a adoção de novos procedimentos, adequados a esta era global.

\section{A revolução tecnológica e a realidade presente e futura da educação e da escola católica}

A mundialização destila, entre outras, as seguintes realidades: competitividade dos mercados, cultura globalizada, economia em bloco, perda de referências éticas acompanhada do surgimento de novos valores, automação dos processos produtivos, aumento do desemprego em escala mundial, forte desigualdade na distribuição dos recursos cognitivos e dos investimentos em pesquisa científica. Tudo isso tem um forte impacto sobre a realidade educacional e sobre o futuro da Escola e da Universidade Católica.

A competitividade cada vez maior, que brota da globalização da economia, fomenta a consciência de que o aprimoramento educacional e o sucesso econômico estão estreitamente ligados. A vinculação entre o ritmo do progresso técnico e a qualidade da intervenção humana sustentam tal afirmação e apontam para a crescente necessidade de formação permanente de agentes econômicos aptos a utilizar as novas tecnologias. Sob a pressão do referido progresso tecnológico e da modernização automatizada dos processos produtivos, acentua-se a demanda por uma educação para fins econômicos.

Tal relação retrata a imbricação entre a educação e a riqueza das nações. Há consenso de que a educação é a chave para o desenvolvimento social e econômico de um país, promovendo o reconhecimento da importância dos recursos financeiros investidos pelos governos na educação escolar. Daí emerge a preocupação, coerente nesta perspectiva, aliás, em avaliar a eficácia de tal investimento. Os procedimentos de avaliação chegam a ocorrer, inclusive, com o estabelecimento de parâmetros que permitam comparações internacionais. Toda essa preocupação justifica-se pela crescente relevância 
Sistema católico de educação e ensino no Brasil: uma nova perspectiva organizacional e de gestão ...

do capital humano e da formação continuada de que devem ser alvo todos os cidadãos, especialmente os produtivos.

Ninguém duvida de que o avanço tecnológico vem oferecendo suporte para o considerável crescimento da riqueza mundial. Nem tampouco que a modernização da economia representou considerável melhoria do bemestar da humanidade. Embora em níveis e formas distintas, essa melhoria dos padrões de vida ocorreu em âmbito quase universal. Da mesma forma, reconhece-se a forma desigual como se deu tal crescimento, acentuando por vezes as fissuras sociais entre povos e no interior de uma mesma nação, através de ritmos de progresso diferenciados entre as macrorregiões do planeta. Fenômeno esse também presente em nosso país.

Superar tais fissuras sociais fica sendo o grande desafio a ser vencido pela humanidade nas próximas décadas, dentro do processo de mundialização, para o qual a educação, seja ela de nível básico, técnico ou superior, será chamada a dar a sua parcela de contribuição. Não compartilho da visão pessimista de muitos quanto ao futuro. Ao contrário, vislumbro a engenhosidade dos homens em construir um mundo melhor para toda a humanidade. Os mesmos elementos e mecanismos que, hoje, estão na base de tais fissuras e desigualdades, poderão retemperar a vida sobre o nosso planeta.

Os paradigmas que norteiam a mundialização e estimulam os processos em rede deveriam estar presentes no horizonte da Escola Católica ao pensar sua ação educativa no advento de um novo século. A nova configuração da economia mundial, aliada à globalização cultural e à tecnologia da informação, deveria mover a Igreja a repensar o papel social político e evangelizador das suas instituições educacionais, bem como o modelo de se organizar em relação a elas. Não é mais possível desvincular a realidade da Escola Católica, seja no campo de sua missão, seja na sua forma de organização, deste contexto emergente com toda a complexidade que lhe é inerente. A Escola Católica deve se sentir provocada em buscar os mecanismos adequados para enfrentar, com a mesma coragem e determinação de seus fundadores e pioneiros de antanho, mais este desafio.

No âmbito da missão educacional e evangelizadora, algumas constatações deveriam povoar as preocupações e as decisões dos atuais gestores da Escola Católica no Brasil. A escola como um todo, vem perdendo a hegemonia no que concerne ao acesso ao conhecimento produzido pelas gerações passadas. A informática universaliza tal acesso, embora, ainda, em escala maior do que é capaz de democratizá-lo. A revolução que a tecnologia patrocina conduz as realidades a constantes mutações e à respectiva indefinição das qualificações profissionais necessárias aos futuros mercados.

Preocupada com esta questão, a American Association of School Administrators encomendou, há uns poucos anos, a um grupo de especialistas, 
uma pesquisa que apontasse o perfil necessário para um profissional sobreviver no Século XXI. O resultado aglutinou-se em torno das seguintes características, em total de 11: capacidade de comunicação; capacidade de articulação e contextualização de informações; habilidade para compreender questões lógicas; habilidade para pensar e solucionar conflitos; familiaridade com informática e novas tecnologias; gosto pela pesquisa; responsabilidade; ética e integridade; flexibilidade e adaptabilidade; disciplina; e, finalmente, capacidade de negociação.

As mutações do mercado e este perfil de profissional nos dizem que a educação precisaria ficar mais flexível, crescer em adaptabilidade e prolongar-se ao longo da vida por retreinamentos contínuos. Por isso, hoje mais do que outrora, devemos focar nossa ação educativa no desenvolvimento de competências e habilidades múltiplas. Isso permitirá, ao cidadão que se deseja formar, a capacidade de tomar decisões rapidamente, em lidar com a automação no cotidiano de sua existência, e de assimilar os paradigmas da revolução gerencial e da qualidade total em sua atividade profissional.

Em suma, a escola deverá formar homens e mulheres que não sejam meros acumuladores de dados, mas sim competentes Gerentes de Informação, com as habilidades cognitivas e operacionais requeridas para a sua aplicabilidade em mercados sempre mais versáteis e imprevisíveis. Em um contexto de constantes mutações, a Escola Católica assume o insubstituível papel de formar cristãos e cidadãos com sólidas referências morais, com equilíbrio e maturidade emocional, com forte sensibilidade social e com grande dose de humanidade nas decisões que deverão tomar ao longo de suas vidas.

A razão instrumental considera o homem e a educação na dimensão funcional-operativa. Nesta perspectiva, desprovida de transcendência, a educação limitar-se-ia à formação profissional ou técnica. A "sociedade globalizada", por si só, não pode fazer um discurso humano. Seu discurso é operativo. Mas ela pode e deve ouvir, e seguramente o fará com sentimento de "saudades", o discurso humano. A Missão da Igreja, não é, pois, estranha à "sociedade globalizada", como a nenhuma realidade humana. Ao contrário, toda realidade humana exige um processo educativo. E, assim, a educação não é mera ação de suplência, mas está no cerne da Missão da Igreja: educar a totalidade do homem, em qualquer tempo e contexto.

Para surpresa de muitos, estes elementos estão muito bem desenvolvidos no Relatório apresentado à UNESCO pela Comissão Internacional sobre a Educação para o Século XXI, presidida por Jacques Delors. Não bastassem as convicções e as referências evangélicas da Igreja, vemos cada vez mais instâncias, como a UNESCO, reafirmarem princípios que são próprios da identidade da Escola Católica, corroborando, assim, o sentido de sua ação pastoral no campo educacional. 
Do impacto da tecnologia na educação anteriormente comentado gostaria de assinalar novamente os seguintes pontos que me parecem essenciais a serem considerados pelo modelo organizacional a ser proposto para a Escola Católica. São eles: flexibilidade, adaptabilidade, "retreinamentos", acesso rápido à informação, mais competência e habilidade do que qualificação, capacidade em tomar decisões rápidas, qualidade total no gerenciamento e automação dos processos de gestão e de controle. Estas posturas podem ser decisivas na relação da Escola Católica com o mercado educacional, considerando que ela não está suficientemente adaptada e preparada para enfrentar a lógica do mercado, por vezes, perversa.

\section{0 desafio da organização de um sistema nacional católico de educação e ensino}

A Escola Católica no Brasil é, hoje, uma instituição bastante desarticulada. A desarticulação se encontra em todos os níveis. Internamente, a Escola Católica, enquanto unidade de base do Sistema Católico de Ensino, é constituída por sua Comunidade Educativa. Esse ideal da Comunidade fica comprometido por força de fatores já assinalados anteriormente, os quais reduzem as relações intracomunitárias e seus agentes a meros componentes de uma relação econômica clássica: a Igreja é proprietária e empregadora, o educador é assalariado, os pais são consumidores e os alunos os usuários. Em que pesem os esforços a fim de criar identificação entre os agentes da comunidade com o projeto da Escola Católica, tais relações seguem extremamente frágeis.

A desarticulação também é externa. As Escolas Católicas no Brasil possuem reduzidíssimos níveis de cooperação e de trabalho em conjunto, mesmo entre escolas situadas em uma mesma cidade e/ ou bairro. Ao contrário, no lugar de uma efetiva cooperação existe acirrada e crescente competitividade. Aspectos que poderiam ser privilegiados para uma ação conjunta, como formação e intercâmbio de pessoal; cooperação técnica e financeira; estratégias de marketing etc., estão longe de ser efetiva realidade entre nós. Hoje, observa-se o "cada um por si e Deus por todos".

Os organismos eclesiais (CRB, ANAMEC, AEC e ABESC) encontramse esvaziados de suas possibilidades em reverter este quadro de desarticulação. A Igreja seguidamente se revela dividida em relação à sua escola. Divisão ideológica e política. A Igreja oficial chega, por vezes, a sustentar teses antagônicas aos interesses da Escola Católica. A Igreja não é uma realidade monolítica, isso nós o sabemos. Mas daí a que suas diversas tendências afetem o que concerne aos aspectos políticos e organizacionais de vital importância para suas escolas, no seio da sociedade civil, é algo a se questionar. O certo é que 
enquanto os organismos eclesiais (ANAMEC, AEC, ABESC, CRB, CNBB, e outros) refletirem tendências e divisões estaremos longe de poder operar em uma estrutura sistêmica de rede, que a globalização aponta como condição para uma ação eficaz e mesmo para a sobrevivência daqui para a frente.

Não há dúvidas de que a Escola Católica continuará necessitando de quem a represente, sustente e coordene a sua ação, em momentos de conflito com os poderes constituídos e/ou outras instâncias da sociedade. A história já demonstrou que a Igreja hierárquica muitas vezes reluta em assumir posturas pela defesa institucional de seus estabelecimentos escolares. Embora ninguém mais questione, ao menos de forma clara e explícita, sobre a validade ou não de a Igreja manter Escolas Católicas, apesar dos seus limites, e considerando as possibilidades potenciais que ela apresenta, hoje, a passividade no trato de certas questões revela, no mínimo, pouco caso para com o seu futuro.

Os administradores de seu patrimônio humano, pedagógico, espiritual, físico e financeiro, se acreditam na Escola Católica, deveriam assumir as suas atuais contradições e agir, inteligentemente, para levá-la a uma outra situação amanhã. $O$ que não é recomendável é acomodar-se à condição de passivos espectadores, diante dos acontecimentos que atingem a Escola Católica, sem a adequada capacidade de mobilização e de resposta ao Estado e à Sociedade, bem como de articulação entre seus agentes, organismos e instituições e aqueles que deveriam compartilhar de sua Missão: os pais e os educadores.

O baixo nível de organização institucional revela-se, inclusive, no seu rudimentar controle estatístico. Nas últimas décadas o único levantamento estatístico realizado sobre a Escola Católica foi o encomendado pela CRB Nacional ao CERIS", publicado em 1990, com o título de "Institutos Religiosos e Sociedades de Vida Consagrada, presença e atuação na área educacional", com dados relativos ao ano de 1988. A pesquisa, realizada a partir do levantamento realizado periodicamente com as Circunscrições Eclesiásticas e as Congregações Religiosas, estava eivada de imprecisões. Mesmo as pesquisas recentemente realizadas sob a coordenação da ANAMEC (1996 e 1999), embora inédita no alcance que obteve, ainda revela os limites da sua organização em âmbito nacional.

Hoje, mais do que nunca, precisamos encarar a urgência de se organizar, a exemplo de tantos outros países, um Sistema Católico de Ensino de abrangência nacional. Certamente, tal sistema extrapola o simples nível de organização de que são dotadas hoje as nossas entidades de caráter nacional. Um Sistema Católico de Ensino, ao contrário dos organismos de âmbito nacio-

2 CERIS - Centro Religioso de Investigação e Estatística, com sede no Rio de Janeiro é órgão ligado à Conferência dos Bispos do Brasil - CNBB. 
nal, não possibilita apenas macroiniciativas, no campo das lutas e das dificuldades de natureza política e econômica com as quais freqüentemente a Escola Católica se depara, mas a constituição de redes também nas pequenas iniciativas e processos.

Como já vimos, as mudanças aceleradas, próprias dos novos tempos, afetam todos os segmentos da vida brasileira, não sendo o campo educacional e a Escola Católica exceções. Mudar é um imperativo na ordem do dia. Inovar também. Para isso é preciso olhar para o futuro, intuir, prever, planejar, dentro de novos paradigmas que a Escola Católica deve estar adotando em seu modelo de gestão e de organização. Para isso, precisa tomar consciência de que, daqui para frente, mais do que sobre a primazia da qualidade, do resultado e da rentabilidade, o modelo organizacional que vier a ser adotado deverá operar em rede e centrar-se sobre a agilidade em adaptar-se às novas demandas e situações e aos novos desafios endógenos e exógenos (ambientes intemo e externo).

A característica de uma aldeia global, organizada em torno da tecnologia da informação, se impõe também à Igreja, às Congregações Religiosas e à Escola Católica. Movendo está última a sair, de uma vez por todas, do estado de fragmentação que debilita os seus esforços, por mais que suas realidades peculiares e institucionais tenham produzido, no passado, e até aqui, uma encantadora variedade de dons e serviços aos seus educandos. Se o processo de mundialização extingue as ilhas, sejam humanas ou geográficas, os muros que separam se fazem, no atual contexto mercadológico, cada vez mais permeáveis no caso específico da Escola Católica.

A formação de redes costuma gerar tanta energia e idéias que os efetivos existentes na Escola Católica não serão certamente suficientes para implantar os projetos desejados. Haverá o nascimento de algo novo, inerente a este dinamismo, sobretudo quando o fruto é a franca cooperação e a real comunhão, e não simplesmente um acelerado ritmo de vida e de iniciativas. A formação de redes, que a globalização nos demanda, se nos apresenta em três âmbitos distintos, cada qual com suas características e desafios próprios, que passo a abordar a seguir de maneira sucinta.

\section{Rede Intra-Mantenedora}

O primeiro destes é o âmbito Intra-Mantenedoras, ou seja, a organização em rede das escolas de uma mesma mantenedora. Para isso, já propus em trabalho meu anteriormente elaborado, a adoção de um modelo de Gestão Centralizada. Os modernos mecanismos para o processamento das informações de que se dispõe atualmente e a avançada tecnologia para transmiti-las facilitam a gestão centralizada. 
A centralização dos recursos financeiros, com uma administração única para o portfólio dos ativos, as receitas centralizadas, os orçamentos consolidados com políticas comuns para investimentos e controle do fluxo de caixa, 0 controle patrimonial, um plano para as reformas e construções, a análise de resultados, a contabilidade unificada em todo o seu processamento, etc., são procedimentos mínimos necessários a este modelo.

A centralização favorece a racionalização de recursos materiais e financeiros, a qualificação dos recursos humanos e a potencializarão de uma série de processos ligados às mais diversas atividades operacionais e estratégias, tais como: suporte técnico na área de sistemas, formação e treinamento de educadores, recrutamento e seleção de pessoal, consolidação de relatórios gerenciais, etc.

Também na dimensão pedagógica e pastoral, as redes permitiriam centralizar alguns processos e controles. Assim estaríamos, ao mesmo tempo, potencializando nossa ação, assegurando a qualidade desejada em nosso serviço e preservando a identidade própria de cada instituição, seja para com os parceiros leigos que conosco trabalham, seja para com os destinatários de nossa ação. Aproveitando da tecnologia à nossa disposição, adotando procedimentos de "intranet", videoconferência e outros, todas estas tarefas ficarão, em futuro próximo, ainda muito mais facilitadas.

\section{Rede entre Mantenedoras}

O outro âmbito é o da criação de Redes entre Mantenedoras, sejam elas de uma mesma Congregação, ou de diferentes Congregações. Não raramente, a caminhada de uma Mantenedora condiciona o projeto político, pedagógico e administrativo de um centro educacional. Neste sentido, ainda que respeitando a vinculação necessária e a interação inevitável entre escola e mantenedora, propugnamos por um maior grau de autonomia entre ambas. Autonomia benéfica e que seria estimulada pela articulação entre mantenedoras, bem como pelo ingresso dos leigos nos quadros dirigentes e decisórios das escolas. Respeitem-se, neste caso, os ditames do Direito Canônico.

Para que essa relação entre mantenedoras possa ocorrer, faz-se necessário recompor as estruturas de governo das Congregações Religiosas em relação aos estabelecimentos escolares. Urge, portanto, aprofundar novas e mais adequadas formas de coordenação para a Escola Católica, até agora totalmente dependentes das estruturas de governo e de controle das Congregações Religiosas.

Estreitando laços, em perspectiva de solidariedade, poder-se-ão favorecer sobretudo as pequenas Mantenedoras, que passariam a contar com 0 
apoio de outras, mais avançadas estas em organização e em disponibilização de recursos. Muitos dos processos apontados anteriormente para uma gestão centralizada poderiam ser assumidos em comum por Mantenedoras distintas.

Promovendo encontros e intercâmbios, criando espaços para se recriar as atuais estruturas organizacionais, ousando em experiências conjuntas, por meio de pequenas iniciativas e projetos, sobretudo locais e regionais, a Escola Católica poderia começar a dar os primeiros passos no sentido da organização de redes de Mantenedoras, onde fatores como proximidade geográfica, similaridade de propostas educacionais ou afinidades históricas poderiam ajudar.

Outra possibilidade é o estabelecimento e a manutenção conjunta de estruturas e/ou instituições por diversas mantenedoras. Ainda que existam riscos e possam ocorrer problemas e dissabores, a força que se conquista e que vai permitir a realização do ideal comum da Educação Católica justificaria a ousadia. As opções jurídicas para se viabilizar tal projeto são as mais variadas e devem ser ditadas pelas características de cada experiência, indo das menos às mais complexas. O importante é a coragem em dar o primeiro passo, sem perder de vista os princípios institucionais.

\section{Rede dos Organismos Nacionais de Educação Católica}

O terceiro âmbito é o dos Organismos Nacionais que coordenam as ações da Escola Católica no Brasil. Hoje, conta-se com inúmeros organismos que definitivamente, no meu ponto de vista, não respondem adequadamente às necessidades institucionais e sociopolíticas da Escola Católica. Concernem mais diretamente a Escola Católica a ANAMEC, a AEC, a ABESC e o CONIEC. As principais conseqüências desta diversidade de organismos atuando na mesma área (ação eclesial no campo da educação formal) são a dispersão de recursos, o desgaste político, o acirramento de divisões internas, a lentidão em deslanchar projetos urgentes e de interesse comum e a desarticulação em questões de vital importância, com visível prejuízo para o presente e o futuro da Escola Católica.

A operação em rede é necessária e urgente neste nível. A forma como estes organismos estão atualmente constituídos, e como eles operam, tem revelado a intenção como intransponível, frustrando, inclusive, expectativas como as presentes quando da criação da ANAMEC em 1993. Isso ocorrerá mais facilmente, alterando o presente quadro, pela modificação da estrutura jurídica desses organismos. Para isso, as opções também seriam diversas: a supressão pura e simples de um ou mais destes organismos; a fusão; a integração em estrutura jurídica distinta das existentes, 
preservando a integridade de todas; ou ainda a opção por modelos de associação como o consórcio ou a federação.

Considerando as diferentes formas de organização existentes alhures, desconheço outro país onde haja tamanha pulverização de organismos nacionais de educação católica nem tampouco tal nível de desarticulação de suas políticas e ações. Não há dúvida que abordo aqui algo polêmico. Não se deve, no entanto, furtar-se a considerar a questão, ainda que possa parecer fora de propósito, ambiciosa ou distante da realidade eclesial e dos atuais problemas da Igreja e da sua Escola Católica.

Diante das inúmeras questões que atualmente nos afligem, e de outras que certamente nos atingirão no futuro, é urgente uma ampla discussão em torno da proposta de instalação de um real e efetivo Sistema Nacional Católico de Educação e Ensino. Organizar a Escola Católica no Brasil de forma sistêmica, possibilitando-lhe operar em rede, e compartilhar processos e projetos dos mais diversos, parece urgente. A instauração de tal Sistema, a partir destes três âmbitos mencionados anteriormente, em que a Escola Católica no Brasil passe a ser um todo harmônico, organizado e articulado, encontrando formas novas e criativas de cooperação, realizando as conquistas necessárias, por meio de uma ação coordenada que parta de suas unidades de base, as escolas, até os organismos (ou a um organismo de âmbito nacional) se lhe converte em um novo horizonte.

Um Programa de Avaliação Acadêmico realizado por todas as Escolas Católicas do país (a exemplo do ocorrido em outros países como México, Argentina e Chile) é exemplo de cooperação em nível nacional, onde a união possibilita processos que seriam inviáveis para um grupo pequeno de instituições. Existem muitas outras áreas onde nossa atuação conjunta representaria inestimáveis ganhos e conquistas para a Escola Católica.

Não se pode desconhecer a força e a responsabilidade social que um Sistema Católico de Ensino (Rede) representaria, bem como o potencial evangelizador e transformador que aí se armazena. Um tênue sinal disto são as poucas Mantenedoras que já atingiram elevados graus de organização e de cooperação entre suas escolas e de parceria com outras Mantenedoras.

\section{Fidelidade a identidade confessional e busca de novos caminhos}

Malgrado as contradições em que A Escola Católica se vê circunscrita, o espaço que a educação formal representa na ação da Igreja e das Congregações Religiosas continua, ainda hoje, quantitativa e qualitativamente, de grande significado. É a própria Igreja quem afirma. 
Sistema católico de educação e ensino no Brasil: uma nova perspectiva organizacional e de gestão ...

Da Carta da Sagrada Congregação para a Educação Católica, de 15 de outubro de 1996, extraímos as seguintes passagens:

as comunidades religiosas têm poucos campos eficazes como as escolas"; "registramos com dor a continuação de algumas dificuldades que levam vossas comunidades a abandonar o setor escolar. A carência de vocações, o desafeto pela missão educativa, as dificuldades econômicas na gestão das escolas católicas, a atração por outras formas de apostolado aparentemente mais gratificantes, bem como outras motivações, fazem orientar os esforços apostólicos em direção a outros setores"; "para esta alta missão formadora, a Igreja, a juventude, as famílias, a sociedade têm necessidade de vós e de vossas escolas.

E ainda o mesmo documento, utilizando-se das palavras de João Paulo II, prossegue dizendo a propósito da Escola Católica: "guardem com o máximo empenho, como a pupila dos olhos, este grande, incomparável serviço à Igreja". E é o mesmo Pontífice quem, na exortação pós-sinodal Vita Consecrata, apelou insistentemente para o retorno dos religiosos ao apostolado educativo.

Com os pés na realidade presente, os dirigentes da Escola Católica deveriam ler os indicadores sociais, políticos, econômicos e mercadológicos disponíveis, tirar partido, da maneira mais adequada e inteligente possível, dos instrumentos que ao seu alcance, e agir para garantir a sobrevivência e a eficácia da Escola Católica no Brasil. Mas agir junto, em conjunto, em rede(s). Na era das redes, quando todos atuam no atacado, é impensável querer continuar a trabalhar e a viver no varejo. Mais do que nunca a união faz a força, do contrário a "mundialização" e o "mercado" engolirão, nas pegadas de seu célere movimento, a Escola Católica e todos aqueles que insistirem em viajar por aí sozinhos.

\section{Referências}

ALVES, Manoel. A Vida religiosa e a educação das elites no atual contexto brasileiro. alguns conflitos e contradições inerentes à educação das elites brasileira pela Igreja dos pobres. In: PAIVA, Vanilda (Org.). Catolicismo, educação e ciência. São Paulo, SP: Loyola, 1991. p. 358.

. El religioso educador face à lãs grandes tendências y retos de L'educacion católica en América Latina rumbo al siglo XXI. Testimonio, Santiago de Chile, n. 152 p. 4-20, nov./dez. 1995.

. O papel das mantenedoras nas organizações da educação católica no Brasil. In: SEMINÁRIO DA ASSOCIAÇÃO NACIONALDE MANTENEDORESDEESCOLAS CATÓLCAS, Brasília, DF. 1996. Anais... Brasília, ANAMEC, ago. 1996. p. 265 
. Leroledel'ecolecatholiquedans laformation deselitesau Brésil 19621992: metacritique d'un systemé complexe. Saint-Denis: Université de Paris, 2000. p. 1200.

ASSOCIAÇÃO Nacional de Mantenedores de Escolas Católicas. Pesquisa sobre as escolas católicas do Brasil - 1996. Brasília, DF, 1997, p. 62.

. Pesquisa sobre as obras sociais da igreja católica e a atuação das escolas católicas - 1998. Brasillia, DF: 2000. p. 61.

ARROCHELLAS, Maria Helena (Org.). Classes médias e a opção preferencial pelos pobres. São Paulo, SP: Paulinas, 1983. p. 131.

CASTELLS, Manuel. A Sociedade em rede: a era da informação: economia, sociedade e cultura. São Paulo, SP: Paz e Terra, 1999. v. 1. p. 617.

CONFERÊNCIA Nacional dos Bispos do Brasil. Para uma pastoral da educação. São Paulo, SP: Paulinas, 1986. p. 137.

. Educação, igreja e sociedade. São Paulo, SP: Paulinas, 1992. p. 86.

CONCILEOecumenique Vatican II. Constitution Dogmatique Lúmenm Gentium, 1964; Consitution Pastoral Guadium et Spes, 1965; Declaration Gravissimum Educationis, 1965 Biblioteca de Autores Cristianos. 27. ed. Madrid: La Editorial Católica, 1975.

CRESPO, Samyra B. de Serpa. Progressismo católico, educação libertadora no Brasil: uma contribuição à história das ideologias. Rio de Janeiro, RJ: UFRy. 1989. p. 391.

CUNHA, Rogério I. A. Teologia da libertação e pedagogia libertadora. Revista de Educação da AEC, Brasília, n. 67, p. 37-50, jan./mar. 1988.

CURY, Carlos R. Jamil. Ideologia e Educação Brasileira: católicos e liberais. 4. ed. São Paulo, SP: Cortez, 1988. p. 201.

GIUSTINA, Osvaldo Della. Rumose desafiosda escola católica. BoletimdaAEC, Porto Alegre, n. 31, 1989.

MORIN, Edgar. Ciência con conciencia. Tradução de Ana Sánchez. Barcelona: del Hombre, 1984. p. 369. Título Original: Science avec Conscienc

. La complexité humaine. Paris: Flammerion, 1994. p. 368.

PAIVA, José Maria. Colonização e catequese 1549-1600. São Paulo, SP: Cortez, 1982. p. 108. 